\title{
El seguimiento de reglas ¿es la praxis de un sujeto? Wittgenstein y las ciencias sociales
}

Pedro Karczmarçyy**

Resumen: En el presente trabajo contrastamos la interpretación de las reflexiones de Wittgenstein sobre el seguimiento de reglas como la "práctica de un sujeto", con una interpretación alternativa que ve en los participantes de los juegos de lenguaje los "sujetos de una práctica". Desarrollamos este punto a través de un análisis de algunas distinciones claves en los Cuadernos azuly marrón (acción significativa y hábito, etc.), que lleva a elucidar conceptos como "obediencia ciega" y "límite de la justificación". En la segunda parte intentamos mostrar que la lectura en términos de "la praxis de un sujeto" habilita una lectura hermenéutica de Wittgenstein en el campo de las ciencias sociales, mientras que la lectura en términos de "los sujetos de una práctica" realiza un conjunto de operaciones críticas cruciales, en particular su negativa a interpretar los fenómenos en términos de causas finales, que llevan a la afirmación de la objetividad de la realidad social, es decir, a la operación de definición del objeto científico a través de la cual se han constituido las ciencias hasta hoy conocidas. Señalaremos para concluir algunos puntos de contacto con las operaciones fundacionales del materialismo histórico.

Palabras clave: Wittgenstein, seguimiento de reglas, obediencia ciega, límite de la justificación, ciencias sociales.

Abstract: The present paper confronts the interpretation of Wittgenstein's rulefollowing considerations as "the praxis of a subject" with an alternative interpretation which thinks of the participants in a language-games as "the subjects of a practice". We develop this contrast through an analysis of some key distinctions in The Blue and Brown Books (meaningful action and habit, etc.) which require elucidation of concepts like "blind obedience" an "the limit of justification". In the second part of the paper we try to show that the "praxis of a subject" view allows an hermeneutic reading of Wittgenstein in the field of the social sciences, while the "subject of a practice" view performs some critical considerations, particularly its denial to understand the phenomena teleologically, which equates to the recognition of the objectivity of social

\footnotetext{
* Profesor, Licenciado y Doctor en Filosofía por la Universidad Nacional de La Plata. En esta institución se desempeña como Profesor Adjunto a cargo de Filosofía Contemporánea. Es Investigador Adjunto de CONICET. Ha publicado dos libros, compilado otros dos y se ha desempeñado como editor de números especiales de revistas. Ha publicado artículos en revistas especializadas, argentinas y del exterior. Dirección electrónica: pedrokarcz@hotmail.com
} 
reality, that it to say, to the operation of definition of scientific object that underlies to the sciences historically constituted. We point in our conclusion some points in common with the foundational operations of historical materialism.

Keywords: Wittgenstein, rule-following, blind-obedience, limit of the justification, social sciences.

En el presente trabajo nos ocuparemos en primer lugar de reconstruir el tratamiento de la distinción entre acción significativa y hábito y otras análogas como "hablar pensando en lo que se dice" en contraste con "hablar sin pensar", o "actuar en base a razones" en contraste con "actuar determinado por un mecanismo causal", prestando atención especialmente a los Cuadernos azul y marrón. Ello nos llevará a revisar el problema de los alcances y los límites de la práctica de la justificación. Estos análisis de Wittgenstein, en los cuales el problema del seguimiento de reglas juega un papel esencial, han sido comprendidos como evidencia de una dualidad de principios metodológicos entre las ciencias sociales y las ciencias naturales, abonando una caudalosa corriente hermenéutica en la interpretación de la obra del filósofo austríaco. ${ }^{1}$ En nuestro trabajo llevaremos a cabo sobre todo una labor crítica, cuestionando la interpretación hermenéutica básicamente por su compromiso con una problemática "antropológica" que hace del concepto de persona una premisa explicativa del seguimiento de reglas. ${ }^{2}$ Por el contrario, nuestra hipótesis es que lo que estos análisis ponen de manifiesto puede comprenderse

\footnotetext{
${ }^{1}$ Ver Winch, Peter, Ciencia social y filosofía, Buenos Aires, Amorrortu, 1972; Apel, KarlOtto, Understanding and Explanation. A Trascendental-Pragmatic Perspective, Cambridge, (Mass.), The MIT Press, 1984; y Taylor, Charles, "Seguir una regla", Argumentos filosóficos, Barcelona, Paidós, 1997.

${ }^{2}$ La expresión "problemática antropológica" la tomamos de Foucault y Althusser, para quienes designa la posición filosófica que tiende a plantear todo problema en el interior del dominio de la finitud humana, esto es, que escoge como premisa de toda elucidación al individuo humano considerado como un sujeto, excluyendo, por considerarla evidente, a esta premisa de su campo de interrogación. Véase Foucault, Michel, ¿Qué es usted, profesor Foucault? Sobre la arqueología y su método, Buenos Aires, Siglo XXI, 2013, pp. 40 y pp. 48-50, y Althusser, Louis, La revolución teórica de Marx, México, Siglo XXI, 1985, pp. 182 y ss.
} 
mejor como un trabajo crítico que deja de lado un conjunto de obstáculos epistemológicos abriendo simultáneamente el espacio para pensar lo social como una articulación de niveles de eficacia. Ahora bien, dicha articulación no puede apresarse apelando a una concepción del seguimiento de reglas como "la práctica de un sujeto", ya que la misma oscurece el problema de la articulación de diferentes niveles de eficacia al colocar en su lugar una dualidad de principios (explicación versus comprensión) que instaura un hiato, es decir, una noarticulación. Argumentaremos que lo que el seguimiento de reglas pone de manifiesto es la necesidad de pensar los efectos de una estructura de estructuras (juegos de lenguaje o formas de vida) sobre los individuos que participan en la misma, eficacia que hace de los mismos (que los constituye como) "los sujetos de una práctica".

En la segunda parte del trabajo nos proponemos examinar algunas consecuencias de esta lectura de la filosofía de Wittgenstein en el pensamiento político y social. Atenderemos al concepto de "reflexividad" que suele vincularse a su perspectiva a partir de la ya clásica interpretación de la relevancia de Wittgenstein para las ciencias sociales realizada por Peter Winch y que goza de un importante predicamento en el pensamiento social contemporáneo. ${ }^{3}$ Intentaremos cuestionar los presupuestos de esta interpretación a través de nuestro análisis del problema del límite de la justificación en los Cuadernos azul y marrón. Utilizaremos nuestra distinción entre la interpretación del seguimiento de reglas como la "práctica de un sujeto", por un lado, y como el efecto que una práctica tiene sobre sus participantes, concebidos como "los sujetos de una práctica", por el otro, para mostrar que mientras que la primera concepción remite al concepto de persona humana y en última instancia al libre arbitrio para dar cuenta de la dinámica de lo social (los cambios en las prácticas, el carácter sobredeterminado de la realidad social, es decir, el desajuste entre la serie de los fenómenos sociales y la de las conductas) la segunda concepción apunta, a partir del rechazo a interpretar los fenómenos en términos de causas finales, a la afirmación de la objetividad de la realidad, es decir, a la operación de definición del objeto científico a través de la cual se han constituido las ciencias

${ }^{3}$ Dicha influencia puede apreciarse a través de la importancia del concepto de reflexividad. Ver Giddens, Anthony Las nuevas reglas del método sociológico, Buenos Aires, Amorrortu, 1997, p. 35, y Corcuff, Philippe Las nuevas sociologias. Principales corrientes y debates, 1980-2010, Buenos Aires, Siglo veintiuno, 2014, pp. 31-33. 
hasta hoy conocidas.

\section{El problema del límite de la justificación en los Cuaderno azul y marrón}

Lo mismo que ocurre con otras obras de Wittgenstein, el Cuaderno azul no se deja reseñar fácilmente. Si bien esta obra tiene, comparada con otras obras del mismo autor, el aspecto de un texto continuo y en la misma no aparecen tan marcadamente las diferentes voces que le dan el tono característico a las Investigaciones filosóficas, ni tampoco presenta la fragmentación en parágrafos numerados que se convirtió en la marca estilística registrada del filósofo vienés, el desarrollo argumentativo nos parece, sin embargo, estar sometido a una lógica semejante al de su obra madura. En efecto, las Investigaciones filosóficas se abren con una vívida caracterización de la concepción antagonista, representada por las reflexiones de Agustín de Hipona sobre su propio aprendizaje de la lengua materna, donde se deja entrever la concepción de la comprensión como un "interior sin exterior", es decir, la idea de que lo esencial en la comprensión consiste en algo así como el diálogo del alma consigo misma. ${ }^{4}$ Esta concepción se exhibe con claridad, por ejemplo, en el hecho de que el pequeño Agustín de Hipona parece haber comprendido el significado de ciertas expresiones antes de haber proferido siquiera una palabra,

\footnotetext{
${ }^{4}$ La concepción agustiniana puede pensarse en términos de una "filosofía del juicio", es decir, una filosofía que hace del conocimiento y la comprensión un asunto de responsabilidad individual, en virtud de que presupone una distinción tajante entre sujeto y objeto, entre interior y exterior. Paul Ricoeur ha enmarcado a la filosofía del juicio en el contexto de la distinción francesa entre "filosofía del concepto" y "filosofía del sujeto", insistiendo en que "si el juicio y no el concepto es la última instancia a la que reenvía la fundación trascendental de la lógica, el juicio es siempre el juicio de alguien y la subjetividad no podría ser anónima." (Ricoeur, Paul, "El lenguaje, la acción, el humanismo" en Ricoeur, Paul (ed.) Corrientes de la investigación en las ciencias sociales, Tecnos-UNESCO, Madrid, 1982, Vol. 4: Filosofía, p. 456). Althusser, por su parte, ha encontrado en la crítica de Spinoza a Descartes un temprano cuestionamiento de la filosofía del juicio; ver Althusser, Louis Psicoanálisis y ciencias bumanas, Buenos Aires, Nueva visión, pp. 99 y ss. La concepción agustiniana, en tanto "filosofía del juicio", se inscribe claramente en el marco de lo que antes hemos denominado "problemática antropológica".
} 
de modo que, si un rayo lo hubiera alcanzado en ese momento, deberíamos decir que se llevó a un pequeño sujeto de comprensión, o un sujeto racional, antes de que fuera un sujeto de habla. Las Investigaciones exhiben la tenacidad con la que esta concepción tiende a rearmarse, a reconfigurarse, a pesar de los embates recibidos. Como el propio Wittgenstein lo señala: "Una figura nos tuvo cautivos. Y no podíamos salir, pues reside en nuestro lenguaje y éste parece repetírnosla inexorablemente." ${ }^{5}$ Así, cuando Wittgenstein analiza la gramática de la expresión "comprensión" y señala el vínculo que la misma guarda con la "aplicación", es decir, con ciertos comportamientos verbales o no verbales, es muy consciente de que, por persuasivo que ello resulte en una primera instancia, este señalamiento no constituye, sin embargo, un embate definitivo a la concepción agustiniana, ya que la misma puede rearmarse, y efectivamente va a hacerlo, a partir de algunas de las consideraciones realizadas y de las expresiones utilizadas en la propia elucidación gramatical. Por ejemplo, una expresión como "la definición ostensiva explica el uso -el significado- de la palabra cuando ya está claro qué papel debe jugar la palabra en el lenguaje", 6 genera la oportunidad para que la concepción agustiniana se reconstituya a propósito de cómo se comprende este "conocimiento" del papel de una palabra en un juego de lenguaje ("... ahora se originan todo tipo de cuestiones en relación con las palabras 'saber' o 'estar claro"' ).

En efecto, las Investigaciones filosóficas ponen de manifiesto, a través de distintas consideraciones, el vínculo gramatical entre comprensión y aplicación, pero la conclusión no llega a imponerse como tal porque en la filosofía hay algo persistente que se opone "a la consideración de los pormenores", 8 algo que hace aparecer a las elucidaciones gramaticales como "pormenores", aspectos accidentales. Wittgenstein compara la situación en la que nos encontramos frente a las elucidaciones gramaticales, que ponen de manifiesto situaciones triviales que están a la vista de cualquiera, pero que, por alguna razón, no llaman la atención, con la de alguien convencido de que un ratón no puede surgir por generación espontánea a partir de harapos y polvo, ${ }^{9}$ lo que

\footnotetext{
${ }^{5}$ Wittgenstein, Ludwig, Investigaciones filosóficas, Barcelona, Altaya, 1999, \115.

${ }^{6}$ Ibidem, \ 30.

${ }^{7}$ Ibidem.

${ }^{8}$ Ibidem, $\int 52$.

${ }^{9}$ Ver ibidem, $\ 52$.
} 
nos arroja a la búsqueda de algo ubicado en otra parte, presumiblemente más profundo. Por ejemplo, la frase "conocer el rol de una expresión en un juego de lenguaje", utilizada en la elucidación de algunas confusiones relacionadas con la operación de la definición ostensiva, es susceptible de ser comprendida a su vez bajo moldes agustinianos, lo que neutralizaría por completo el terreno ganado con la crítica de la concepción del nombrar de Agustín. En consecuencia, la exposición de las Investigaciones prosigue con la consideración de la expresión "conocer el rol de una expresión en un juego de lenguaje" y a partir de allí la exposición se desarrolla con la misma lógica. Wittgenstein anticipa los movimientos de un contendiente que cede parte de su territorio cuando no tiene más remedio, pero que está dispuesto a utilizar las palabras con las que se realizan las elucidaciones gramaticales, aprovechando la evidencia con la que se presentan, para intentar cercar una nueva parcela en la que cultivar su concepción.

Considerada de esta manera, como un ataque persistente a una determinada figura del funcionamiento del lenguaje, esto es, como un embate a una concepción filosófica rústica, pero susceptible, por un lado, de refinarse de diferentes modos, y por el otro, de renacer a partir de lo que parecen ser sus cenizas, las Investigaciones filosóficas no carecen de unidad, sino que se presentan como un embate articulado, cuyos pasos no son arbitrarios. La unidad en cuestión no es una unidad interior de un principio, de la que resultaría una obra orgánica, organizada en torno a un fundamento que funcionaría como un leitmotiv generador de un sistema filosófico. La unidad de las Investigaciones no es la de una estructura expositiva, sino la de un combate incesante. Unidad agónica, entonces, comandada por la extrema sensibilidad del autor de la obra para detectar las posibilidades de malentendidos. ${ }^{10}$ No cabe, entonces, hablar de saltos temáticos arbitrarios, aunque hay que reconocer que el material podría organizarse de manera diferente, por la razón teórica elemental de que nunca nos acecha una sola posibilidad de malentendido de una expresión, máxime cuando la propia dilucidación de los malentendidos hace uso de nuevas expresiones, que son, a su vez, susceptibles de ser comprendidas erróneamente,

\footnotetext{
10 Véase, por ejemplo: “Toda explicación tiene que desaparecer y sólo la descripción ha de ocupar su lugar. Y esta descripción recibe su luz, esto es, su finalidad, de los problemas filosóficos" (Ibidem, \109).
} 
por ejemplo, bajo moldes agustinianos.

Algo semejante ocurre con el Cuaderno azul (y también con el Cuaderno marrón, al que nos referiremos luego). En esta obra hay una unidad discernible que enlaza los diferentes temas que aborda, pero esta unidad no reside en el desarrollo positivo de un contenido o tesis, sino en la continuidad de un embate. El Cuaderno azul se abre con el examen de la naturaleza del "proceso" denominado "pensar", concebido como concomitante con la emisión de signos, es decir, la concepción del pensar entendido como aquello que insuflaría "vida" a unos signos que, de otra manera, se verían reducidos a ser meros ruidos o marcas vacías en el papel. Puesto que el tipo de confusión que cometemos acerca del proceso del pensar se repite a propósito de otros "procesos" (como "creer", o "esperar", o "sentir"), estos son examinados en detalle, lo mismo que el presupuesto común a todos estos diferentes procesos, la idea de que existiría algo así como "el elemento" en el cual acaecerían todos los acompañantes presuntamente encargados de dar vida a los signos, esto es, "el medio de la mente". Esta concepción es caracterizada por Wittgenstein como una vía descarriada, como el fruto de una confusión que no se reconoce a sí misma como tal. Esta vía descarriada es la filosofía misma (en su sentido tradicional) o la metafísica, en relación con la cual el libro propone pensar que se trata de una empresa sin esperanzas de concreción, mostrando cómo la idea de la mente y sus sucedáneos son supuestos quiméricos a los que, sin embargo, les atribuimos un índice de eficacia para el que no podemos ofrecer ningún modelo. ${ }^{11}$ Se revela así que la presunta eficacia de la mente radica en su carácter oculto, de medio extraño, lo que convierte a esta idea en una suerte de refugio para la ignorancia. ${ }^{12}$ Pero el Cuaderno azul no se limita a esta operación negativa, sino que se propone, también, mostrar que la suposición del proceso mental del pensar (o el de esperar, creer o sentir) es también innecesaria, en la medida en que el examen de las diferentes dificultades que presenta concebirlos como procesos acompañantes peculiares da lugar a una concepción alternativa del lenguaje que permite comprender, no tanto qué es lo que hace que los signos

${ }^{11}$ Es decir, la suposición de que "el mecanismo de la mente debe ser de un tipo completamente peculiar para hacer lo que la mente hace" (Wittgenstein, L., Cuadernos azuly marrón, Barcelona, Planeta-Agostini, 1994, p. 32).

12 "Era precisamente el carácter oculto del proceso mental lo que uno necesitaba para sus propósitos" (Ibidem, p. 31). 
adquieran vida, sino qué es lo que nos llevaba a buscar un acompañante. Una vez que entendemos qué es lo que nos hacía ir a la búsqueda de quimeras deberíamos llegar a comprender también de qué manera los signos "adquieren vida", sin que haya algo diferente de los signos mismos que inyecte vida en ellos, o, como lo expresa el propio Wittgenstein en la obra que estamos analizando, a comprender que: "si tuviésemos que designar algo que sea la vida del signo, tendríamos que decir que era su uso."13

La pregunta por lo que da vida al signo o a la frase es desplazada por la referencia al uso del signo. Ahora bien, el uso parece remitir a la relación de los signos entre sí: "El signo (la frase) obtiene su significado del sistema de signos, del lenguaje a que pertenece. Rudimentariamente, comprender una frase significa comprender un lenguaje". ${ }^{14} \mathrm{Si}$ hablamos de un desplazamiento del problema es porque, si comprender una frase o un signo depende de la comprensión de un lenguaje, o de un sistema de signos, ahora la dificultad retorna bajo la forma en que es entendida la "comprensión de un lenguaje o un sistema de signos". La comprensión de un sistema retorna como algo que acompaña a la frase, como un estado de conciencia ("algo de una esfera oculta") que acompaña a la frase. ¿Se trata de una conciencia del sistema total de los signos o de algo semejante? Wittgenstein desalienta consecuentemente esta posibilidad: "cualquier cosa que le acompañase [a la frase] sería precisamente otro signo."15

El movimiento es entonces doble. Por un lado, se señala la dificultad que presenta concebir a aquello que da vida (es decir, significado) a la frase o signo en términos de un acompañante. Por otra parte, se señala que comprender un

${ }^{13}$ Ibidem, p. 31. En realidad, es dudoso que el Cuaderno azul elucide este problema. La dificultad es, a mi juicio, la siguiente: si bien reconocer o comprender, etc. no pueden identificarse con un proceso mental, subsiste el hecho, altamente curioso, de que quien reconoce o comprende lo hace usualmente de manera correcta. Hasta que no podamos entender este hecho de manera adecuada, la búsqueda de un mecanismo no cesará, y el contraargumento filosófico será visto como evidencia de que se identificó erróneamente el mecanismo, o de que quizá quepa buscar un mecanismo de otra clase. En el Cuaderno azul este punto no está, a nuestro entender, suficientemente claro. ${ }^{14}$ Ibidem, p. 31.

${ }^{15}$ Ibidem, pp. 31-32. 
signo o una frase es comprender un lenguaje o un sistema de signos, ${ }^{16}$ pero inmediatamente se desalienta, con toda coherencia, que esto consista en tener conciencia, ya sea de manera patente o subsidiaria, del sistema total de signos, que se vería reducido a ser otro acompañante de la frase, un signo (más complejo) adosado al signo inicial, del que cabría preguntar nuevamente cómo es que le da vida a la misma. ${ }^{17}$ Descartado que el pensar sea un acompañante del uso de los signos, Wittgenstein señala al uso mismo como el lugar donde debe buscarse una elucidación. Ello da lugar a la declaración, tal vez la más polémica que aparece en el Cuaderno azul, según la cual "pensar es esencialmente la actividad de operar con signos." 18

El siguiente movimiento que nos interesa destacar tiene que ver con el vínculo entre las dos observaciones que surgen como consecuencia del ataque a la concepción del pensar como un proceso que acompaña la emisión de las palabras: las observaciones sobre las combinaciones entre signos, por un lado, y las observaciones sobre la actividad de operar con los mismos, por el otro, en la que aparece un énfasis claramente anti-tractariano. En efecto, Wittgenstein acomete el análisis de la expresión "[tener] una sensación en mis manos de que el agua está a tres pies bajo la tierra." ${ }^{19} \mathrm{Si}$ bien la misma se presenta espontáneamente como un sinsentido, Wittgenstein no procede a un rechazo palmario de la misma, sino que realiza una operación que podríamos llamar el descubrimiento de un sentido latente en un sinsentido patente. En efecto, Wittgenstein nos dice de esta expresión que: "combina palabras bien conocidas, pero las combina de manera que no comprendemos todavía. La gramática de esta expresión tiene que sernos explicada", ${ }^{20} \mathrm{y}$ tal explicación proviene de la reconstrucción de las circunstancias en las que podríamos aprender a usar una

${ }^{16}$ En el Cuaderno marrón, Wittgenstein va un poco más profundo e indica que comprender ("ser guiado") es ser capaz de responder a distintas combinaciones de signos, en contraste con lo que podría considerarse una reacción automática, una reacción de memoria, por ejemplo. Ver ibidem, pp. 136 y 156.

${ }^{17}$ Vemos así esbozarse la posibilidad de un regreso infinito, del que nos ocuparemos luego.

${ }^{18}$ Ibidem, p. 33; ver también p. 43.

${ }^{19}$ Ibidem, p. 37.

${ }^{20}$ Ibidem. 
expresión semejante, ${ }^{21} \mathrm{o}$ incluso, si no pudiéramos aprender a usarla en primera persona, su significado podría aclararse mediante una explicación que nos permita usarla en tercera persona.

El significado o la gramática de una expresión puede ser enseñada o explicada (y también, establecida o modificada). Una combinación de palabras que parece carecer de sentido, puede revelar tenerlo, o puede adquirirlo, por medio de una explicación que clarifique las circunstancias y los criterios con los que se utiliza. Pero, sin embargo, uno podría preguntarse: "¿qué se nos enseña o explica cuando se nos enseña el significado que nos permite hacer uso de la expresión?", es decir, la cuestión sigue siendo, ahora travestida, “¿qué es lo que aprehendemos cuando comprendemos el lenguaje?”. ${ }^{22}$ Se trata de una pregunta difícil, que suscita múltiples problemas; para comenzar, el de llevarnos a buscar algo que se aprehende o capta cuando ocurre eso que llamamos "aprender el significado". Para prevenir este malentendido, nos advierte Wittgenstein, debemos estudiar "la relación entre aprender el significado y hacer uso de una palabra", relación que, según nuestro autor, pone de manifiesto "las diferentes relaciones posibles entre una regla dada y su aplicación." 23

El tratamiento de Wittgenstein de esta cuestión (el problema de las "relaciones posibles entre una regla dada y su aplicación") tiene dos pasos. Por un lado, Wittgenstein toma como ejemplo "el proceso de estimar una longitud", ${ }^{24}$ es decir, una de las formas más concretas y literales de "aplicar una regla", para señalar la variedad de casos que abarca eso que llamamos "estimar una longitud" (y a fortiori, "aplicar o seguir una regla"). Wittgenstein nos propone considerar cuatro casos:

1) Alguien pregunta: “¿cómo estimó usted la altura de este edificio?" Yo respondo: "tiene cuatro plantas; yo supongo que cada planta tiene unos quince pies de alto; luego debe tener alrededor de sesenta pies."

2) En otro caso: "yo conozco aproximadamente lo que parece una yarda

\footnotetext{
21 “...la contestación del adivino no nos hubiese confundido si nos hubiese dicho que él había aprendido cómo estimar la profundidad” (Ibidem, p. 38).

22 Ver Rhees, Rush, "Prefacio" a Wittgenstein, L., Cuadernos azuly marrón, ed. cit., p. 17.

${ }^{23}$ Wittgenstein, Cuadernos azuly marrón, p. 37.

${ }^{24}$ Ibidem, p. 38.
} 
a esta distancia; luego debe tener alrededor de cuatro yardas de alto."

3) O bien: "yo puedo imaginar un hombre alto que alcance aproximadamente hasta este punto; luego debe tener alrededor de seis pies sobre el suelo."

4) O: "no sé; parece tener una yarda."

Este último caso va a enredarnos. Si alguien pregunta: “¿qué sucedió en este caso cuando la persona estimó la longitud?" la contestación correcta puede ser: "miró la cosa y dijo 'parece tener una yarda de longitud'." Esto puede ser todo lo que sucedió. ${ }^{25}$

La lista es muy relevante. En los primeros tres casos encontramos ciertos procesos intermediarios, mientras que en el cuarto caso Wittgenstein advierte que "va a enredarnos", debido, precisamente, a que en el mismo no hay proceso intermediario alguno. La dificultad es, vertida en jerga mentalista (o agustiniana) que en este último caso no hay nada que parezca insuflar vida en las palabras. Lo paradójico del cuarto caso es que, aunque estamos estudiando el vínculo entre la regla y su aplicación, parecemos toparnos sólo con la aplicación, sin la propia regla. Para expresarlo como una pregunta: ¿puede llamarse "aplicación de una regla" a un proceso que consista en la mera aplicación (es decir, la acción acorde con la regla, por ejemplo, el acto de estimación: "parece tener una yarda"), sin la intermediación de la regla misma?

Si bien Wittgenstein no formula esta pregunta, aborda sin embargo la cuestión que subyace a la misma a través de un rodeo que lo lleva a considerar el aprendizaje del lenguaje, la enseñanza de la regla. Recordemos que el problema en cuestión era la relación entre aprender un significado y hacer uso de una palabra. Wittgenstein señala que "Aprender a estimar puede considerarse, hablando de modo general, en dos relaciones distintas con el acto de estimación: o como una causa del fenómeno de la estimación o como proporcionándonos una regla (una tabla, un plano o una cosa de este estilo) de la que hacemos uso cuando estimamos." 26

Volvamos ahora a lo que motiva la advertencia de Wittgenstein acerca del cuarto caso de estimación de la longitud, es decir, aquel en el que no se

${ }^{25}$ Ibidem.

${ }^{26}$ Ibidem, p. 38-39. 
verifica ningún proceso intermediario, sino sólo la aplicación. ¿Cuál es el problema con el mismo? La observación que acabamos de citar nos da una indicación preciosa. Esto es, si a veces aprender a estimar nos da una regla (tabla, etc.) de la que hacemos uso cuando estimamos, ¿en qué medida cabe decir que un caso como el que consideramos, en el que no se hace uso concretamente de ninguna regla, es un caso genuino de "estimar de acuerdo con una regla"? ¿En qué medida cabe hablar en este caso de una relación entre una regla (la yarda, por ejemplo) y sus aplicaciones? ¿No será más bien el caso que consideramos la puesta en acto de un automatismo, de un mecanismo ciego? $\mathrm{O}$, para decirlo con la terminología más específica del Cuaderno azul, ¿en qué medida se puede decir que quien simplemente mira la cosa y dice una frase como "parece tener una yarda", estima la longitud pensando en lo que hace? ¿No es el ejemplo considerado un caso flagrante de "hablar sin pensar"?

Intentemos ver de qué modo las dos maneras distintas de considerar la enseñanza o aprendizaje aludidas por Wittgenstein ayudan a abordar esta cuestión. Por una parte, la enseñanza puede considerarse como un entrenamiento. En tal caso, la tarea de la enseñanza es hacer que se produzca una asociación (entre una palabra y una imagen, entre una palabra, una imagen y una acción, o simplemente entre una palabra y una acción). Wittgenstein señala que, así considerada, la enseñanza "es la causa de los fenómenos de comprensión, obediencia, etc." ${ }^{27}$ En tanto productora de un mecanismo causal, de una "conexión asociativa" en el ejemplo, la enseñanza no es un fenómeno que deba intervenir necesariamente, sino meramente una hipótesis, de allí que Wittgenstein señale, a propósito de ello, la posibilidad de que tales procesos (asociación, sensación de reconocer, etc.) lleguen a la existencia sin que medie un proceso de enseñanza, es decir, de manera innata. ${ }^{28}$ Como lo dice el propio Wittgenstein con un giro enigmático: "Una regla, en la medida en que nos interesa, no actúa a distancia". ${ }^{29}$ Bajo el supuesto de que lo que nos interesa es la gramática, esto significa que el proceso bipotético de la enseñanza no forma parte de la gramática [del modo de uso] de la expresión "estimar una longitud" (o de "seguir o aplicar una regla"), lo que, naturalmente, no quiere decir que los resultados de este proceso hipotético no formen parte de la gramática de la

\footnotetext{
27 Ibidem, p. 40.

28 Ibidem.

${ }^{29}$ Ibidem, p. 41.
} 
expresión considerada.

La enseñanza puede considerarse, por otra parte, como aquello que provee una regla que está implicada, ella misma, en los procesos de comprender, obedecer, etc. En este sentido, la enseñanza es considerada como una explicación. ${ }^{30} \mathrm{El}$ tratamiento de esta cuestión en el Cuaderno azul resulta a primera vista un poco sinuoso. En primer lugar, Wittgenstein introduce, de una manera un poco abrupta, la distinción entre "proceso acorde con una regla" y "proceso que implica una regla", es decir, una distinción que si no es exactamente la distinción entre "concordar accidentalmente con una regla" y "seguir una regla de manera deliberada", tiene grandes similitudes con la misma. Lo abrupto de la distinción se atenúa un poco si consideramos que, además de una distinción metafísica que discierne, en "el mobiliario del mundo", entre los procesos acordes y los procesos deliberados de seguir una regla, esta distinción tiene su "tierra natal" en el contexto de enseñanza, donde para el maestro o la maestra es crucial distinguir entre, por un lado, los aciertos accidentales del alumno y, por el otro, aquellos aciertos que denotan un aprendizaje de la tarea en cuestión. Sin embargo, el tratamiento de la cuestión en el Cuaderno azul carece de los recursos conceptuales que podrían permitir llevarla a cabo (habrá que esperar para ello hasta el tratamiento de la gramática de "poder", "ser capaz" y "capacidad" en el Cuaderno marrón). El tratamiento de este problema en el Cuaderno azul adopta el modelo del "establecimiento de una conexión”, que Wittgenstein usó otras veces en este texto (por ejemplo, para clarificar las dificultades del uso en pasado de "referir" o en el establecimiento del lugar dolorido por el hablante). ${ }^{31}$ Lo que distingue uno de otro proceso es que, en el primer caso (proceso acorde con una regla) se produce una aplicación que concuerda con una regla determinada sin que la expresión de la regla forme parte de los procesos de comprensión. En cambio Wittgenstein considera que si para obtener los resultados, para llegar a la aplicación (que naturalmente está sometida a la misma indeterminación), se hubiese escrito la expresión de la regla (la expresión algebraica de la regla de

\footnotetext{
${ }^{30}$ Esto muestra que adiestramiento y explicación no son excluyentes uno de otro, sino que son, cuando menos en ciertos casos, dos aspectos de un mismo proceso.

31 Ibidem, pp. 69-70.
} 
elevar al cuadrado en el ejemplo considerado) entonces se habría establecido una conexión, por lo cual podría afirmarse que "esta regla estaba implicada en un sentido en el que no lo estaba ninguna otra regla". 32

En contraste con la enseñanza como adiestramiento, en la que la regla "actúa a distancia" y no es de interés para el estudio gramatical emprendido, la enseñanza considerada como explicación parece actuar in situ, al proveer una regla implicada en el proceso de comprender.

La noción de "regla implicada" modela el concepto de razón que aparece en el Cuaderno azul. Dar una razón es indicar un camino que conduce a una acción, en algunos casos indicando el camino seguido efectivamente, mientras que, en otros casos, consiste en "describir un camino que conduce allí y que está de acuerdo con reglas aceptadas". ${ }^{33}$ La respuesta podría haber sido producida "automáticamente" 34 por alguien, pero cuando se le requiriera la razón de su acción, éste podría dar una razón de la segunda clase, en cuyo caso hablaríamos de una justificación post-hoc. ${ }^{35} \mathrm{En}$ el primer caso, en cambio, hablaríamos de una razón existente (actual reason). ${ }^{36}$

32 Ibidem, p. 40. El problema del regreso de las reglas ya está planteado en sus trazos generales en el Cuaderno azul, disperso en varios ejercicios destinados a cuestionar que la diferencia entre el hablar significativo y el hablar "mecánicamente (sin pensar)" (Ibidem, p. 63). Por ejemplo, al analizar lo que podríamos denominar la intencionalidad de una imagen, aquello que hace que la misma sea acerca de una cosa y no de otra, Wittgenstein considera la hipótesis de que un método de proyección de la imagen resolvería esta cuestión. Pero inmediatamente indica: "tal proceso no puede ser nunca la intención misma. Pues siempre podríamos habernos propuesto lo contrario reinterpretando el proceso de proyección" (Ibidem). De esto resulta que el modelo "signo-interpretación" como propuesta de diferencia específica del hablar significativo con el hablar mecánico, que sería meramente "signo", no nos lleva a buen puerto, porque "siempre que interpretamos el signo de un modo u otro, la interpretación es un nuevo símbolo añadido al antiguo" (Ibidem).

${ }^{33}$ Ibidem, p. 43.

${ }^{34}$ Tal es la expresión usada en p. 42.

35 Ibidem, p. 42.

${ }^{36}$ Un poco más adelante Wittgenstein señala que "Dar una razón es como dar una operación de cálculo mediante el cual se ha llegado a un cierto resultado" (Ibidem, p. 
La justificación post-hoc nos habilita a pensar que el caso que aparecía como problemático, el de estimar una longitud espontáneamente, sin un proceso intermediario, puede no obstante estar basado en una razón, en la medida en que la gramática de esta expresión habilita que se considere como una razón no sólo el registro del camino seguido, sino también la mención de un camino que podría haberse seguido y que conduce al resultado. La regla está implicada, en este caso post-factum. Insistimos en ubicar esta reflexión bajo el modelo del establecimiento de una conexión, utilizado también en el examen del imperfecto de "referir" (to mean), ${ }^{37}$ ya que reconocer en ciertos casos el carácter performativo de la provisión de una razón (mediante una declaración del tipo "lo hice por esta o aquella razón") ayuda a prevenir la ilusión retrospectiva según la cual habría un "proceso correspondiente" (estado mental u operación real, material) para cada razón provista.

Veamos con más detalle la manera en que estas observaciones nos ayudan a comprender la dificultad que se planteaba a propósito de nuestro ejemplo. En efecto, la dificultad aparece debido a que "se tiene la idea de que si se comprende y se obedece una orden, tiene que haber una razón para que la obedezcamos como lo hacemos; $y$, de hecho, una cadena de razones que se remonta hasta el infinito. Es como si se dijese: 'Dondequiera que estés, tienes que haber llegado allí de algún otro sitio, y a este lugar previo de otro lugar; y así ad infinitum'." 38

La idea de una cadena infinita de razones parece surgir debido a dos razones distintas. Por un lado, "pensar que una línea de una cierta longitud consta de un número infinito de partes porque es divisible indefinidamente; es decir, porque no hay límite a la posibilidad de dividirla." 39 No es inmediatamente claro cómo deba entenderse este fragmento. ¿Cuál es la

43). Esta observación es interesante, ya que por un lado la misma parece reafirmar la interpretación de la razón como razón existente, en el sentido de operación efectivamente realizada, pero la misma podría interpretarse también en el sentido de que una operación en un cálculo es una operación según reglas aceptadas, donde dados ciertos argumentos se obtiene determinado resultado, siendo la operación controlable por otros.

${ }^{37}$ Ver ibidem, p. 69.

${ }^{38}$ Ibidem, p. 42.

${ }^{39}$ Ibidem. 
contraparte, en el terreno de las razones, para la posibilidad de división? El candidato más plausible parece ser la provisión de justificaciones post hoc, ya que, no estando limitada a la descripción de un proceso acaecido, de una operación realizada, se podría siempre, en principio, proveer una razón ulterior. Por otra parte, la idea de una cadena infinita de razones podría surgir de la consideración de la extensión efectiva de la cadena de razones en procesos concretos de comprensión (es decir, los procesos concretos que acaecen en una persona, en su cerebro o en sus estados mentales, en los casos en los que decimos que hay comprensión). Al respecto, Wittgenstein señala: "si uno se da cuenta de que la cadena de razones existentes tiene un comienzo, no se inquietará más por la idea de un caso en el que no haya razón del modo en que se obedece la orden." 40

A esta altura es necesario hacer dos preguntas que nos ayudarán a entender mejor el asunto que estamos tratando. Por un lado, ¿en qué sentido tienen un comienzo las razones existentes?; por otra parte, ¿los caminos aceptados, convenidos, son ilimitados?

En relación con la primera pregunta, la cuestión debe examinarse por el lado de las razones implicadas. En efecto, normalmente un individuo dará un número limitado de respuestas a la pregunta "¿por qué cumplió la orden (siguió la regla) de esta manera?", si lo que está haciendo es darnos una descripción de lo que hizo efectivamente.

La respuesta a la segunda pregunta es un poco más compleja. En un sentido debemos responder por la afirmativa, por dos motivos: por un lado, porque tal cosa está supuesta en la analogía de la posibilidad de dividir y la posibilidad de dar razones. En el Cuaderno azul no llega a verse del todo claro sobre este punto, para ello hay que esperar hasta el tratamiento del problema del infinito mediante la distinción entre el juego limitado y el ilimitado en el Cuaderno marrón, por un lado, y un análisis de la continuación bizarra de una serie, desarrollado también en el Cuaderno marrón según líneas muy semejantes a las que repetirá el celebérrimo parágrafo 185 de las Investigaciones. ${ }^{41}$ Estas observaciones nos dan una idea clara de la manera en la que siempre se puede generar una razón más, de la manera en que algunos juegos de lenguaje pueden

\footnotetext{
${ }^{40}$ Ibidem.

${ }^{41}$ Ibidem, p. 181.
} 
contener instrucciones para generar, ad infinitum, nuevos caminos según reglas aceptadas a partir de caminos según reglas aceptadas ya conocidos. En el Cuaderno azul hay algunas observaciones muy condensadas ${ }^{42}$ con una orientación semejante acerca del uso del imperfecto de 'referir', 'refería', en las que se dice que el uso de un nombre propio "hace que parezca que la conexión entre nuestro pensamiento (o la expresión de nuestro pensamiento) y la cosa sobre la cual pensamos tiene que haber subsistido durante el acto de pensar", ${ }^{43}$ con las cuales Wittgenstein ofrece un modelo de cómo surge la ilusión de una cadena infinita de razones existentes que antecedería al desarrollo empírico (al uso o aplicación) de la misma. También van en esta línea las observaciones sobre "saber seguir adelante". El uso de esta expresión, en particular si soy interrumpido en mi emisión, al desarrollar una serie por ejemplo, da pie a la ilusión de la antecedencia de la serie a su desarrollo oral o escrito. Estos análisis nos dan algunas indicaciones precisas sobre la gramática de la expresión "el pensamiento ya estaba listo desde antes".

Con esto hemos señalado que las observaciones de Wittgenstein sobre la analogía entre la infinita divisibilidad y la posibilidad de dar un paso más, de proveer un argumento ulterior, como fuente de la ilusión de una cadena infinita de razones, suponen la existencia de otros juegos de lenguaje cuya gramática, más o menos incomprendida, se proyecta como una cadena de razones antecedente infinita. Dicho de otra manera, la incomprensión de la gramática de expresiones como "sin límite" "ad infinitum" y de una expresión como "el pensamiento ya estaba listo entonces", parecen ser la condición para que se suscite la confusión que estamos considerando.

La confusión respecto de casos como éste nos lleva a pensar el contraste entre automatismo y acción inteligente en términos de la presencia de algo en la mente, un acompañante o la carencia del mismo (la cadena infinita de

${ }^{42}$ Véase, por ejemplo: “[se] busca una justificación cuando no hay ninguna. Exactamente lo mismo que en el caso en que una persona cree que la cadena de razones tiene que ser ilimitada. Piensen en la justificación de la realización de operaciones matemáticas mediante una fórmula general; y en la cuestión: ¿Nos obliga esta fórmula a hacer uso de ella en este caso concreto como lo hacemos?" (Ibidem, p. 107).

43 Ibidem, p. 69. 
razones), que establecería la diferencia entre ambos procesos. Deshacer esta confusión nos permite volver a pisar el terreno del uso efectivo del lenguaje con mayor seguridad. En efecto, una vez que se reconoce de dónde proviene la exigencia de una cadena infinita de razones (lo que nos lleva a decir "itiene que haber!") se puede afrontar con menos inquietud el caso del que nos venimos ocupando desde el comienzo de este trabajo, es decir, aquel en el que no hay una razón del modo en que se ejecuta la orden.

Tener en claro de dónde proviene la exigencia de una cadena infinita de razones nos previene de levantar la exigencia de una cadena infinita de razones, de la tentación de proponerla como un criterio, inútil a fin de cuentas, de lo que distingue una acción 'automática' de una 'consciente', 'deliberada', 'inteligente', etc.

Sin embargo, la cosa no termina allí. Independientemente de la exigencia de postular una cadena infinita de razones, como modelo equívoco de la gramática de una expresión como "el pensamiento estaba allí desde antes", tenemos que considerar otra posible confusión, la que brota de la ambigüedad de la pregunta “¿por qué?”, que induce a la confusión entre razón y causa. En efecto, nos dice Wittgenstein:

Así, cuando la cadena de razones ha llegado al límite y se hace todavía la pregunta “¿por qué?”, se tiene inclinación a dar una causa en lugar de una razón. Si, por ejemplo, a la pregunta "¿por qué pintó usted precisamente este color cuando le dije que pintase una mancha roja?" se contesta: "Se me enseñó una muestra de este color y se me pronunció la palabra 'rojo' al mismo tiempo; $y$, por tanto, este color me viene ahora a la mente siempre que oigo la palabra 'rojo"', entonces se ha dado una causa de la acción y no una razón. ${ }^{44}$

La confusión en cuestión es de orden gramatical, es decir, una confusión sobre el funcionamiento de estas expresiones Por un lado, en la respuesta se proporciona evidencia empírica, de la que cabe razonablemente dudar, como resulta obvio si recordamos lo que dijimos antes acerca de que las conexiones asociativas que resultan del aprendizaje podrían ser innatas, o si imaginamos,

${ }^{44}$ Ibidem, p. 42. 
por caso, que el aprendizaje de un término como 'rojo' no tuvo lugar del modo, ya de por sí bastante implausible, que indica el sujeto interrogado en el fragmento considerado: supongamos que disponemos de evidencia de que una reforma pedagógica realizada con el lema de una "vuelta a la naturaleza" propugnó también el abandono de las muestras de color, y que por la edad del sujeto, podemos colegir que 'rojo' probablemente le haya sido enseñado con manzanas y churrascos, etc. y no con material pedagógico artificial como muestras de colores. Una duda acerca de una hipótesis causal de esta clase es siempre legítima y posible, pero sin embargo, por el lugar en que aparece esta hipótesis en el ejemplo (como respuesta a la pregunta "¿por qué hiciste tal cosa?") la posibilidad de duda parece estar eliminada. Se "da origen así a la confusión de que un motivo (razón) es una causa de la que tenemos conciencia inmediatamente, una causa "vista desde el interior", o una causa experimentada." 45

Tenemos entonces otro sentido en el que llegamos al límite de la justificación: cuando las razones existentes se acaban o faltan, inquirir por la razón, formular la pregunta “¿por qué?” puede inducir a presentar una causa (una hipótesis causal) como si fuera la razón o motivo de la acción.

Podemos ahora volver al giro enigmático "Una regla, en la medida en que nos interesa, no actúa a distancia". Dijimos más arriba que este giro se refiere al hecho de que la enseñanza, en cuanto causa del comportamiento, no forma parte de la gramática de la expresión 'seguir una regla' o 'aplicar una regla', en el sentido de que no se puede apelar a la enseñanza para dar una razón o justificar un comportamiento como acorde a una regla. Sin embargo, ello no quiere decir que los resultados de la enseñanza no formen parte de la gramática de la expresión 'regla'. Wittgenstein sostiene al respecto: "sólo podemos conjeturar la causa, pero conocemos el motivo" 46 indicando que es un enunciado gramatical. Con este enunciado gramatical volvemos a ser confrontados, como tantas veces en la obra de Wittgenstein, con el hecho de que cada paso en la elucidación de un problema o confusión se presta a nuevos malentendidos.

En cierto modo, la conexión conceptual entre la seguridad práctica en la manifestación de los propios motivos y razones, es decir, la espontaneidad con

45 Ibidem, p. 43.

46 Ibidem. 
la que se nos presenta el uso de expresiones como "mi motivo...", la ilegitimidad de dudar en primera persona acerca de si uno mismo hizo algo con una razón u otra, tal como viene realizada en proposiciones gramaticales por medio de la expresión "conocer" (conjeturamos la causa, conocemos el motivo) es correcta aunque inexacta. De manera análoga: "Sólo yo sé si siento dolor" en tanto enunciado gramatical, no remite a un hecho que garantizaría este saber, sino que intenta poner de manifiesto un rasgo del uso de las expresiones de dolor, ${ }^{47}$ donde la expresión 'saber' indica que no se puede dudar de las propias expresiones de dolor, que la expresión de incertidumbre en primera persona carece de sentido, porque a quien duda si siente dolor no lo calificamos como "yo doliente". En otros términos, un enunciado gramatical no es un enunciado acerca del mundo, sino acerca de la cuadrícula con la cual hablamos del mundo. La regla gramatical que se enseña con "sólo tú puedes saber si tienes dolor" no remite, entonces, a un fundamento o a una evidencia factual especial ("no lo dudas, porque lo sabes", debido a una evidencia a la que se accedería en la interioridad de cada cual, de lo que el motivo o la razón entendida como la "causa experimentada" que venimos de considerar sería un ejemplo), sino que una descripción más adecuada de su uso es: "porque no dudas al manifestar tus estados mentales, "sabes" (decimos que sabes) qué es el dolor, si lo dudaras, ya no lo sabrías". Este es el límite de la justificación, todo el misterio reside en que la confianza del hablante, sus usos espontáneos están capturados por una regla gramatical.

Podemos ahora comprender cómo ingresan en la gramática las consecuencias de la regla considerada como causa del comportamiento. La gramática establece que la expresión confiada de un motivo o razón, expresión confiada que el individuo no obtiene por medio de criterios o comparaciones, usualmente resultado de un proceso causal ligado al aprendizaje, cuenta como evidencia gramatical (como un criterio) para que otros reconozcan mi propio comportamiento como una acción deliberada y me atribuyan rótulos como el de 'agente racional', 'sujeto de pensamiento', u otros que me califican como un hablante competente.

Esto que acabamos de señalar se deja apreciar mucho mejor en una

\footnotetext{
${ }^{47}$ Ver un análisis análogo en Investigaciones filosóficas $\ 247$, a propósito de "Sólo tú puedes saber si tuviste la intención".
} 
aproximación ulterior que Wittgenstein hace a esta cuestión, esta vez desde la perspectiva de la tercera persona. Si bien el ejemplo considerado es la atribución de dolor de muelas, el mismo se adapta bien a nuestros propósitos. En efecto, se considera allí el uso de la expresión "tal y tal tiene dolor de muelas", que puede aplicarse en base a sintomas, es decir, en base a acompañantes más o menos regulares del fenómeno en cuestión, de orden causal, como por ejemplo una mancha roja o una hinchazón en la mejilla que acompañan al dolor de muelas, o bien en base a criterios, como la conducta de dolor que consiste en llevarse la mano a la mejilla. Si en una atribución en base a un criterio semejante se formulara la pregunta:

“¿Y por qué supone usted que al gesto de él de llevarse la mano a la mejilla le corresponde un dolor de muelas simplemente por el hecho de que cuando usted tiene dolor de muelas se lleva la mano a la mejilla?" Nos veremos muy mal para contestar esta pregunta y nos daremos cuenta de que aquí tocamos suelo rocoso, es decir, hemos descendido a las convenciones. ${ }^{48}$

Lo que nos interesa señalar es que aquí, por decirlo de algún modo, se cierra "el círculo de los desplazamientos". Recordemos que la inquietud inicial era cómo un comportamiento inteligente puede ser compatible con los automatismos que se reconocen apenas se observan los casos concretos de lo que denominamos "comportamiento inteligente" ("estimar longitudes", por ejemplo). La observación gramatical que Wittgenstein nos ayuda a exhumar nos muestra que dichos automatismos están instalados de manera constitutiva en la gramática de nuestro lenguaje acerca de comportamiento inteligente. ${ }^{49} \mathrm{En}$ efecto, los comportamientos automáticos, o si se quiere suavizar la expresión, confiados (es decir, seguros, carentes de vacilación), en el uso de ciertas expresiones vinculadas con el comportamiento inteligente (seguir una regla, dar una razón, etc.), están instalados en la gramática, es decir, ofician de criterios

48 Wittgenstein, Cuadernos azuly marrón, p. 53.

${ }^{49}$ Esta cita del Cuaderno marrón es ilustrativa al respecto: "No hay acto de captación, de intuición, que nos haga usar la regla como lo hacemos en el punto particular de la serie. Sería menos confuso llamarlo un acto de decisión, aunque también esto es desorientador, pues no tiene que realizarse nada parecido a un acto de decisión, sino tal vez sólo un acto de escribir o de hablar" (Ibidem, p.183). 
para las atribuciones por otros. De esta manera, cuando llegamos a los mismos nos topamos con "el suelo rocoso", más allá del cual no podemos ir. Se podría decir, entonces, que pasamos de la inquietud acerca de cómo el comportamiento racional o inteligente es compatible con los comportamientos automáticos, a una elucidación que nos muestra que estos comportamientos automáticos son constitutivos de nuestro discurso acerca del comportamiento inteligente, del actuar comprensivo, en la medida en que configuran la evidencia criterial de la que disponemos para tales atribuciones. Llegar al suelo rocoso, es llegar al terreno de "lo dado", de lo que "hay que aceptar" para poder ver con claridad, de manera sinóptica, nuestro lenguaje. Pero, sin embargo, es claro que hay algo que, de manera persistente, se opone a esta consideración de la gramática, algo que hace aparecer a estas consideraciones como pormenores sin importancia.

El análisis ofrecido en el Cuaderno azul adolece, sin embargo, de algunas insuficiencias. En primer lugar, si bien la colocación del automatismo como piedra de toque de la elucidación gramatical es adecuada, y crucial, el resultado del análisis no parece ser lo suficientemente fino como para poder trazar de modo adecuado la diferencia de categoría entre dos clases de conceptos que denominamos "estados mentales", ejemplificados por la comprensión y el dolor respectivamente. No faltan observaciones en el Cuaderno azul que nos den la pista de la diferencia, como por ejemplo la que indica que lo que distingue el hablar pensando lo que se dice del hablar sin pensar "puede muy bien ser algo que sucede antes o después de que se hable" 50 y no algo que ocurre mientras se babla. Sin embargo, más allá de esta observación, la diferencia permanece imprecisa.

El Cuaderno marrón reescribe algunas de las consideraciones que acabamos de revisar a partir de una comprensión mucho más profunda de lo que implica "seguir una regla". ${ }^{51}$ Así es que nos encontramos con una

${ }^{50}$ Ibidem, p. 73; ver también p. 69.

${ }^{51}$ Véase también el tratamiento de la ambigüedad de la pregunta “¿Por qué?” en el Cuaderno marrón, p. 123: "Si nuestro caso 14 c) [un caso que impacta como una actuación automática, análogo al caso 4) considerado en Cuaderno azul, p. 38 que venimos de analizar, PK] les preocupa, ustedes pueden tender a decir: "¿Pero por qué trajo precisamente esta pieza de material? ¿Cómo la ha reconocido como la correcta? 
distinción entre regla y orden. La segunda es entendida como la "descripción del camino que ha de seguir B [quien recibe la orden]". ${ }^{52}$ De la regla se nos dice que lo que la caracteriza es "ser aplicada repetidamente, en un número indefinido de casos". ${ }^{53}$ La noción de orden así presentada es análoga a la noción de "regla implicada" cuyo uso en el Cuaderno azulvenimos de analizar.

La clave de la diferencia entre los planteos de Cuaderno azul y Cuaderno marrón radica, a nuestro entender, en el tratamiento de la noción de "capacidad". En efecto, esta noción juega un papel crucial en el Cuaderno marrón. A partir del contraste entre 'ser guiado' y "no ser guiado" por un conjunto de símbolos, es decir, a partir de un contraste análogo al de responder guiado por un conjunto de símbolos y responder a ellos de memoria, donde el contexto pedagógico parece ser el contexto más característico de uso de esta distinción, su "tierra natal" de acuerdo a la observación de Wittgenstein en Investigaciones $\ 116$, Wittgenstein nos lleva a examinar la diferencia en términos de la capacidad para reaccionar a combinaciones diversas de signos, contrastándola con la reacción al conjunto de signos como un todo. Ello nos lleva a considerar la gramática de "capacidad", de "ser capaz".

Las expresiones de posibilidad ('poder', 'ser capaz', etc.) tienen una gramática difícil de dilucidar debido a la tendencia a considerarlas como el nombre de un estado, lo que es una figura incrustada en nuestras formas de expresión que resulta completamente desorientadora. ${ }^{54}$ Ello nos lleva a buscar un estado que corresponda a lo que Wittgenstein llama una "experiencia sensorial estacionaria", 55 es decir, la percepción duradera de un estado o

\footnotetext{
¿Mediante qué?” Si ustedes preguntan 'por qué', ¿preguntan por la causa o por la razón? Si es por la causa, es bastante fácil discurrir una hipótesis fisiológica o psicológica que explique esta elección bajo las condiciones dadas. La tarea de las ciencias experimentales es comprobar tales hipótesis. Si, por el contrario, preguntan por una razón, la respuesta es: 'No se necesita que haya habido una razón de la elección. Una razón es un paso que precede al paso de la elección. ¿Pero por qué cada paso tiene que ir precedido por otro?"'.

52 Ibidem, p. 131.

53 Ibidem.

54 Ibidem, p. 155.

55 Ibidem, p. 137.
} 
propiedad, cuando lo crucial de la gramática de dichas expresiones es que se las atribuya a partir de pruebas (tests). En torno a este núcleo, debemos reconocer que las expresiones de capacidad son un conjunto diverso que guarda entre sí parecidos de familia, a saber: "hay, por ejemplo, el elemento de conjetura (que algo se comportará de un modo determinado en el futuro); la descripción del estado de algo (como una condición del hecho de que se comporte de un modo determinado en el futuro); el cómputo de determinadas pruebas que ha realizado alguien o algo." 56

En este análisis se encuentra, a nuestro entender, el núcleo del problema del seguimiento de reglas, lo que permite colocar mejor los énfasis del análisis gramatical. En efecto, ahora el diagnóstico acerca del surgimiento de la idea de una cadena infinita de razones se vincula directamente con el problema de seguir una regla. Así es que a la pregunta "¿qué significa seguir la regla correctamente?" se le podría responder que "el paso correcto es el que está de acuerdo con la regla tal como nos referimos a ella, tal como se la entendió" y a partir de aquí surge la idea de que al referirnos a la regla, en una orden por ejemplo, ocurrieron, de algún modo, un número infinito de actos de significación. Cuestionar esta idea no es cuestionar que quien dio la orden de seguir una regla sabía lo que quería que su alumno hiciera en cada caso, sino cuestionar la concepción de "saber" que proyecta la idea de una cadena infinita de razones. En efecto, la gramática de "saber" debe elucidarse de acuerdo con la gramática de "ser capaz" a la que hemos aludido.

Ahora bien, hay un punto en el que el Cuaderno marrón no modifica el rumbo adoptado por el Cuaderno azul, sino que, a lo sumo, lo precisa, o mejor, lo radicaliza. En efecto, en lo que concierne al automatismo y a su colocación gramatical, Wittgenstein sostiene:

No hay acto de captación, de intuición, que nos haga usar la regla como lo hacemos en el punto particular de la serie. Sería menos confuso llamarlo un acto de decisión, aunque también esto es desorientador, pues no tiene que realizarse nada parecido a un acto de decisión, sino tal vez sólo un acto de escribir o de hablar. Y la falta que tendemos a hacer aquí y en mil casos semejantes está marcada por la palabra "hacer" tal como la hemos usado en la frase "No hay acto de captación que nos haga usar la regla tal como lo

${ }^{56}$ Ibidem, p. 155. 
hacemos”, porque hay una idea de que 'algo tiene que hacernos' hacer lo que hacemos. Y esto vuelve a enlazarse con la confusión entre causa y razón. No necesitamos tener razón alguna para seguir la regla tal como lo hacemos. La cadena de razones tiene un límite. ${ }^{57}$

Utilizar sin criterios algunas expresiones no es, dentro de un juego de lenguaje, un defecto, sino algo esperado y estimulado por el mismo. Es por ello que, cuando llegamos al terreno de las convenciones, las expresiones de duda en primera persona carecen de sentido, es lo que destacamos en el análisis de proposiciones gramaticales como "sólo puedes conjeturar la causa pero conoces el motivo". La seguridad al seguir una regla es un criterio para que otro considere que yo sigo, mal o bien, una regla. Así, por ejemplo, la expresión "No sé si soy yo u otro quien siente dolor", ubicada en el terreno de las convenciones, no sería un enunciado falso, sino carente de sentido. De tratarse de un enunciado falso tendríamos que reconocer como una proposición al enunciado: "Sé quién siente dolor (al decir "siento dolor")", y entonces deberíamos poder preguntar por las razones (criterios, justificaciones) de este saber. Antes bien, se trata de un enunciado que carece de sentido, porque las expresiones seguras, esas que al hablante "se le escapan", son un paradigma con el que se entrelaza el uso de los términos 'yo' y 'dolor', de manera que, como en los otros casos que consideramos, no cabe imaginar lo contrario.

En este mutuo sostén de la primera y la tercera persona encontramos la respuesta a la pregunta ¿qué es para una convención estar más allá de las justificaciones? Retomando un ejemplo de Investigaciones filosóficas $\int 407$, podríamos decir que, si bien la capacidad para identificar al sujeto doliente, la realización de enunciados con 'dolor' en tercera persona, no se vería impedida por la dificultad de parte del emisor de la expresión de dolor para identificar al doliente, habría, sin embargo, consecuencias para quien profiriera esta duda y tuviera esta dificultad. En Investigaciones filosóficas $\$ 288$, Wittgenstein indica: "si alguien dijese "No sé si es un dolor lo que tengo o es algo distinto", pensaríamos algo así como que no sabe lo que significa la palabra castellana

${ }^{57}$ Ibidem, p. 183. 
'dolor' y se lo explicaríamos." 58

\section{Wittgenstein y las ciencias sociales}

Para concluir este trabajo deseamos realizar algunas reflexiones acerca de las consecuencias que la línea de análisis que presentamos ofrece para revisar el uso dominante del pensamiento de Wittgenstein en el campo de las ciencias sociales. Intentaremos vincular estas consecuencias con algunas repercusiones que estos planteos tuvieron en el interior del propio pensamiento wittgensteiniano, de acuerdo con una sugerencia que realiza Rush Rhees en el prólogo a los Cuadernos azuly marrón.

Comencemos por la caracterización de la problemática dominante en la cual se desenvuelve la apropiación del pensamiento de Wittgenstein en el interior de las ciencias sociales. En un estudio reciente, Albert Ogien situó el interés de la sociología por Wittgenstein en el marco de la crisis del positivismo sociológico, que llevó a la aceptación de "la idea de que el enfoque científico no se reduce a la producción de una explicación estrictamente causal de los fenómenos". ${ }^{59}$ Frente a ello, Wittgenstein se presenta como un aliado de los sociólogos desde la influyente lectura de las implicaciones de su pensamiento para las ciencias sociales que realizó Peter Winch en 1958. ${ }^{60}$ En esta obra, Peter Winch convertía al problema de seguimiento de reglas en el modelo de la acción significativa, lo que le daba pie para extraer consecuencias de largo alcance, diferenciando la metodología de las ciencias sociales de la metodología de las ciencias naturales en virtud de que en los estudios sociales un estudioso no debe confrontarse sólo con la discusión que otros investigadores pueden hacer

\footnotetext{
${ }^{58}$ Ver Investigaciones filosóficas $\ 85$ sobre la conexión entre falta de duda (certera) y seguimiento de reglas. Por ejemplo: "Así es que puedo decir que el indicador de caminos no deja después de todo ninguna duda abierta. $\mathrm{O}$ mejor: deja a veces una duda abierta y otras veces no. Y ésta ya no es una proposición filosófica, sino una proposición empírica."

${ }^{59}$ Ogien, Albert, Las formas sociales del pensamiento. La sociología después de Wittgenstein, Buenos Aires, Nueva visión, 2007, p. 10.

${ }^{60}$ Winch, Peter, Ciencia social y filosofía, Buenos Aires, Amorrortu, 2008.
} 
de sus observaciones y experimentos, sino que está confrontado inevitablemente con un objeto de estudio configurado por un mundo social estructurado por reglas. El científico social, en consecuencia, no sólo debe seguir las reglas de la cultura científica de la que forma parte, sino que debe participar de las reglas de la cultura que está estudiando. Tiempo después Anthony Giddens le dio el nombre de "doble hermenéutica" a este fenómeno. ${ }^{61}$

Hanna Pitkin en su comentario de las posiciones de Peter Winch distingue entre una posición "extrema", cuando este autor sugiere que "una explicación no enmarcada en los propios términos del actor no es una explicación en absoluto, no puede proporcionar comprensión alguna de la acción humana, incluso no tiene sentido" 62 y una posición "moderada", según la cual "las acciones pueden ser explicadas en términos ininteligibles para los actores, pero únicamente si aquellos términos son traducibles a los del propio actor." ${ }_{33}$ Ogien intentó sintetizar lo esencial de la influencia de Wittgenstein mediante la figura de lo que él denomina el "rompecabezas de Wittgenstein" acerca de la posibilidad misma de una ciencia social. Según Ogien, Wittgenstein mostró la diferencia de naturaleza entre meramente describir y comprender una práctica. De esta diferencia se sigue que la serie de los hechos empíricos brutos implicados en las prácticas (descripciones de comportamientos o conductas, por ejemplo) no puede correlacionarse uno a uno con la serie de los hechos sociales, cuya identificación supone comprensión, participación en la forma de vida. Por ejemplo, quien estudie una sociedad determinada podrá comprobar que hay una cierta correlación entre realizar ciertos movimientos con el brazo y saludar. Pero, y éste es el punto esencial, esta correlación no vale sin excepciones, los participantes en la práctica son capaces de reconocer formas de saludo que no consisten en este movimiento (saludos circunspectos, que pueden reducirse a una mirada) y también casos de movimiento del brazo del todo análogos al saludo, pero que no son casos de saludo (por ejemplo, el

${ }^{61}$ Ver Giddens, Anthony, Las nuevas reglas del método sociológico, Buenos Aires, Amorrortu, 1997.

62 Pitkin, Hanna, Wittgenstein: el lenguaje la política y la justicia. Sobre el significado de Ludwig Wittgenstein para el pensamiento social y político, Madrid, Centro de estudios constitucionales, 1984, p. 363.

${ }^{63}$ Ibidem, pp. 363-364. 
movimiento realizado al espantar una mosca, o en una obra teatral). En consecuencia, identificar un saludo (que pertenece a lo que denominamos "la serie social") no se reduce a la aprehensión de una regularidad subyacente que sería accesible a un observador que no comprenda la situación social en cuestión (lo que llamamos "la serie de las conductas"). A raíz de ello, identificar un saludo parece suponer una cierta comprensión de la forma de vida, de las actividades y propósitos que se están llevando a cabo, etc. Ahora bien, puesto que la capacidad de hacer excepciones es crucial en esta comprensión, ello implica que, aunque el sujeto de esta comprensión pueda expresar algunos de los criterios de inteligibilidad en los que se apoya su comprensión, los mismos no subsumirán, por fuerza, a todas las excepciones. La comprensión parece implicar, así, una forma de saber hacer, es decir, una forma de participación en la práctica, irreductible a un análisis empírico.

Se comprende el dilema que esto plantea a los sociólogos: el de bloquear la posibilidad de encuadrar el trabajo propio de la sociología en el marco de un estudio puramente empírico. Por un lado, no importa cuántos datos se obtengan, la descripción empírica no alcanzará a la comprensión (ésta requiere alguna forma de saber hacer o capacidad de participar en la práctica); por otra parte, la elucidación de una práctica realizada por el sociólogo o el antropólogo a través de la explicación de los criterios de inteligibilidad que operan en la misma parece quedar a una distancia abismal respecto al objeto de estudio. En consecuencia, ¿es posible estudiar empíricamente una práctica sin tomar parte en ella, sin comprender el sentido que debe dársele a una práctica desde el interior de ella misma? ${ }^{64}$

Esta dificultad ha suscitado un recentramiento de la interpretación del planteo de Wittgenstein en la forma sujeto. Esto es evidente en el caso de Peter Winch, que hizo de la condición de la "reflexividad" la piedra basal de la distinción entre reglas y hábitos, entre acción significativa, accesible a la comprensión, y hábitos opacos a la comprensión, que deben describirse causalmente. ${ }^{65}$ Ya hemos indicado en un trabajo previo que Winch se desvía,

\footnotetext{
64 Ver Ogien, op. cit., pp. 55-61.

${ }^{65}$ Véase un juicio diferente sobre la importancia de Winch en la filosofía de las ciencias sociales en Descombes, Vincent, "Philosophie des représentations collectives", History
} 
con esta elucidación, de la recomendación wittgensteinana de ofrecer una descripción gramatical del uso de las expresiones, sin importar lo "altas" o "bajas" que parezcan, para poner a la noción de reflexividad como el fundamento de la distinción ontológica entre naturaleza y cultura. ${ }^{66}$ Ello tiene como consecuencia nada menos que reintroducir al sujeto del libre arbitrio como el sujeto del seguimiento de reglas, sujeto concreto o particular que queda entrampado en el planteamiento de un círculo trascendental (círculo ideológico): el sujeto particular remitirá ahora eternamente al sujeto comunitario implicado en la elucidación del "uso establecido" o de la "costumbre" para poder distinguir lo que le parece correcto de lo que es correcto, círculo que se exhibe a sí mismo en cuanto tal en el hecho de que en esta elucidación de la noción de regla el vínculo entre el uso establecido y el caso concreto cuya corrección está en cuestión es una relación de tipo acaso...

Otra vertiente de interpretación, representada por autores como Charles Taylor ${ }^{67}$ y John McDowell, ha tendido a extraer una consecuencia ligeramente diferente del planteo de Wittgenstein. Esta vertiente ha tendido a descargar el problema de las excepciones sobre una forma de saber práctico, sobre un saber hacer, que estaría en el fundamento del seguimiento de reglas. John McDowell, por ejemplo, ha desarrollado esta línea de interpretación en su trabajo "Virtue and Reason". ${ }^{68}$ Allí, McDowell argumenta que la resolución wittgensteiniana del problema del seguimiento de reglas (que no hay una regla que pueda determinar cómo seguir una regla) consiste en la postulación de una forma de saber práctico del tipo del estudiado por Aristóteles en el dominio de la ética.

of the Human Sciences, Vol. 13, N 1, 2000, pp. 37-49. Según Descombes, la importancia de Winch radica en haber resuelto el problema de las representaciones colectivas, eludiendo la implicación de un sujeto colectivo mediante la indicación de que la complementariedad de los estatus sociales es una relación interna. Entendemos que nuestra elucidación del problema del límite de las justificaciones conserva la relación interna de dicha complementariedad (la primera y la tercera persona se sostienen mutuamente en las reglas gramaticales) sin comprometerse con una noción sustantiva de reflexividad como lo hace el enfoque de Descombes.

66 "Wittgenstein, Winch, Kripkenstein y la posibilidad de la crítica", Cuadernos de Filosofia, $\mathrm{N}^{\mathrm{o}}$ 30-31, 2012-2013, pp. 7-37.

${ }^{67}$ Taylor, Charles, "Seguir una regla", en Argumentos filosóficos, Barcelona, Paidós, 1997. ${ }^{68}$ McDowell, John, "Virtue and Reason", Mind, Value and Reality, Cambridge, Harvard University Press, 1998. 
McDowell pone de manifiesto este punto a través del problema de la "unidad de la virtud" planteado por el estagirita, explicando que lo que está en juego en el mismo es que, incluso bajo el dudoso supuesto de que las virtudes particulares pudieran resolverse en imperativos (lo que las convertiría en formas de saber teórico; por ejemplo "ser considerado" sería: "actúa teniendo en cuenta los sentimientos de los demás") la posesión de virtudes individuales no haría de alguien una persona virtuosa, porque para ser virtuoso no sólo se requiere conocer y adecuarse a los requerimientos de las distintas virtudes particulares, sino sobre todo estar en condiciones de hacer excepciones. En ciertas condiciones, en las que se impone un requerimiento de justicia, es natural dejar de lado la exigencia de la consideración por los sentimientos de otros, hacer una excepción en relación a la misma, mientras que en otras circunstancias la búsqueda de la justicia a toda costa puede constituir un vicio. En razón de que no se puede, por principio, confeccionar una lista de las excepciones, el saber del virtuoso y de quien sigue una regla serían necesariamente formas de saber práctico. ${ }^{69}$

Lo común a ambas líneas de interpretación radica en que el carácter práctico que Wittgenstein reconoce en los juegos de lenguaje es entendido en los términos de "la práctica de un sujeto". Hay sin embargo una lectura alternativa del carácter práctico de los juegos de lenguaje que no hace del mismo la praxis de un sujeto, sino que hace de los participantes o agentes en el juego de lenguaje "los sujetos de una práctica".

Ya hemos expuesto las líneas maestras de esta lectura alternativa al realizar nuestro análisis de los Cuadernos azul y marrón. Intentaremos ahora exhibir el alcance de esta interpretación poniendo en paralelo las conclusiones que extrajimos a propósito de los Cuadernos con algunos planteamientos de Sobre la certeza donde se abordan precisamente las evidencias sin fundamento o razón que las sustente que es lo que encontramos ubicado en el límite de la justificación en los Cuadernos azul y marrón (los comportamientos espontáneos o confiados). En este texto Wittgenstein parte de un ejemplo de G. E. Moore, la proposición "Aquí hay una mano", proferida por Moore ante un auditorio

${ }^{69}$ Esto acerca a Wittgenstein a la hermenéutica, ver Karczmarczyk, Pedro, Gadamer: aplicación y comprensión, La Plata, Edulp, 2007, donde realizo una lectura de Wittgenstein a la que hoy no suscribiría en varios puntos. 
que podía observarlo levantar su mano. Con este ejemplo, Moore pretendía demostrar la existencia del mundo exterior. Wittgenstein pudo desentrañar el efecto retórico de esta extraña prueba de Moore reparando en que la certeza del filósofo inglés no es algo meramente personal, sino algo general, común, compartido por un grupo de hablantes. ${ }^{70}$ Las proposiciones escogidas por Moore no sólo son indudables para Moore, sino en general para cualquier lector ("si él las sabe, todos las sabemos"71). El estatuto peculiar de estas proposiciones alcanza para explicar el efecto de la declaración de Moore, el hecho de que la misma no suscite dudas o voluntad de cuestionarla en su auditorio, pero este efecto no alcanza para calificarlas como saber. Ello implicaría olvidar que existen fenómenos como "Creía saberlo/estaba convencido. Pero no lo sabía." $72 \mathrm{Si}$, en un juego de lenguaje, estas evidencias son compartidas, ello ocurre porque su "reconocimiento" es un requisito para participar del mismo.

Ahora bien, el sentido de la explicación gramatical que nos propone Wittgenstein en Sobre la certeza no es: "Porque reconocemos como evidentes las mismas proposiciones, participamos en el mismo juego de lenguaje", lo que estaría en la línea de concebir a los juegos de lenguaje como prácticas de sujetos que surgen de la interacción continuada de muchos seres humanos. Antes bien, lo que hay que entender es que para los hablantes no está en cuestión aceptar o rechazar estas proposiciones. Las mismas cuentan como criterios de lo que significa comprender el sentido de las palabras, de manera tal que quien las cuestionara se tornaría ininteligible y resultaría apartado del juego de lenguaje; en esto consistía, a fin de cuentas, de acuerdo con nuestra interpretación, el hecho de que una convención esté más allá de las justificaciones. La elucidación propuesta por Wittgenstein toma la forma de un condicional contrapuesto: "Si no reconocemos la evidencia de estas proposiciones, entonces no somos habilitados para participar en el juego de lenguaje". Esto implica que los juegos de lenguaje son anteriores e independientes de cualquiera de sus participantes, no en el sentido de que existan aparte de ellos, sino en el sentido de que la

\footnotetext{
${ }^{70}$ Ver Wittgenstein, L., Sobre la certeza, Barcelona, Gedisa, 1991, \84, 440.

${ }^{71}$ Ibidem, $\$ 100$.

${ }^{72}$ Ibidem, $₫ 21$.
} 
posición de participante se define en el propio juego de lenguaje. La certeza se puede pensar entonces como el efecto del juego de lenguaje en el registro vivencial ("Lo que se mantiene firme lo hace no porque sea intrínsecamente sea obvio o convincente, sino porque se sostiene en lo que le rodea"73), algo próximo a lo la concepción spinozista de lo "imaginario" desarrollada por Althusser. ${ }^{74}$ En resumen: Wittgenstein muestra que las evidencias son el efecto de una exigencia que los juegos de lenguaje imponen sobre los pequeños infantes humanos, a quienes se designa como aspirantes al juego desde el propio juego de lenguaje, y que los individuos humanos son constituidos como hablantes al responder al juego de lenguaje con certeza, de modo que el "reconocimiento" de las certezas produce un ocultamiento del rol constitutivo del juego de lenguaje sobre la práctica de sus sujetos. ${ }^{75}$

Pensar a los participantes de los juegos de lenguaje como los sujetos de una práctica implica un conjunto de problemas novedosos y también una serie de reacciones preventivas. La más importante es cuestionar la visión que busca para la distinción entre acción inteligente y los automatismos un fundamento más allá de las prácticas, de donde proviene la importancia que se le otorga a la noción de reflexividad. La resignificación de los automatismos o de la "obediencia ciega" por parte de Wittgenstein despertó el fantasma del conductismo, y el filósofo austriaco temió, consecuentemente, ser leído de ese modo. Esta lectura es inadecuada, por dos razones principales. Por una parte, porque la lectura de la articulación entre los automatismos y la estructura de las prácticas que proponemos no anula el desajuste entre la "serie de las conductas" y la serie de los "hechos sociales", sino que, simplemente, no busca la solución al mismo a través de la conversión del seguimiento de reglas en la práctica de un sujeto, lo cual, según hemos visto, no es una genuina solución, sino la instauración de un hiato, disimulado bajo la implantación de un círculo,

${ }^{73}$ Ibidem, $₫ 144$.

${ }^{74}$ Véase Althusser, Louis, Ideología y aparatos ideológicos de Estado. Frend y Lacan, Buenos Aires, Nueva visión, 1988.

${ }^{75} \mathrm{En}$ mi trabajo "Las condiciones y la naturaleza del discurso crítico: el debate entre hermenéutica y teoría crítica", Discusiones filosóficas, Vol. 11, $\mathrm{n}^{\circ} 16$, realizo un acercamiento al análisis wittgensteiniano de la gramática de "reconocimiento", confrontándola con los usos de Gadamer y Habermas de esta expresión. 
en el mejor de los casos uno tan grande que hace imperceptible su curvatura.

El desajuste puede comprenderse mejor si pensamos los automatismos implicados en el seguimiento de reglas a partir de lo que parece ser su forma más básica, la relación que se entabla en el entrenamiento, entre las reacciones presupuestas por el mismo, que podemos denominar forma de la vida, destacando así su dominante biológica, y las formas de vida sociales y culturales, que podemos denominar formas de vivir, destacando que su dominante es social e histórica. Las "formas de la vida" humana (en el sentido de reacciones innatas presupuestas) no admiten una mera descripción conductista, como si se tratara de un hecho físico bruto, porque lo que pueda ser considerado como forma de la vida humana depende de las formas de vivir en las que tiene que insertarse. Wittgenstein, decíamos, intentó rechazar preventivamente una apropiación conductista de su pensamiento. Es que, a partir de lo que acabamos de señalar, el pensamiento de Wittgenstein señala más bien una eficacia en sentido contrario: desde las formas de vida sociales ya constituidas hacia la biología. ${ }^{76}$ En el momento de pensar en la adquisición de la lengua materna, Wittgenstein se topaba con una forma de eficacia peculiar instalada en los propios juegos de lenguaje, en las formas de vida sociales. Esta eficacia va desde las formas de vivir hacia las formas de la vida y resulta particularmente difícil de percibir, porque su mecanismo opera por paradojas: atribuyendo (requiriendo) a los individuos agencia independiente, imponiendo el reconocimiento espontáneo de este requisito (véase la gramática de expresiones del tipo de “¡ahora sé cómo seguir!”) como una condición para su participación en los juegos de lenguaje.

El reconocimiento de esta dirección de análisis ha permitido realizar un importante avance en la elucidación de la gramática de "seguir una regla". ${ }^{77} \mathrm{El}$ funcionamiento de nuestro discurso normativo, del que el discurso sobre reglas es una ilustración paradigmática, presenta dos puntos sobresalientes: (i) que

\footnotetext{
${ }^{76}$ Es en este sentido que proponemos leer una expresión clave como: "Lo que hay que aceptar, lo dado son formas de vida" (Wittgenstein, L., Investigaciones filosóficas, parte II, p. 517).

77 Seguimos aquí la reconstrucción de esta gramática propuesta por Kripke en su "solución escéptica". Ver Kripke, Saul, Wittgenstein a propósito de reglas y lenguaje privado, Madrid, Tecnos, 2006.
} 
mediante sus expresiones ('comprender', 'poseer tal o cual concepto', 'seguir tal o cual regla', etc.) se evalúa a los individuos, es decir, se los clasifica, de manera tal que se los habilita o excluye, o bien se modeliza su participación en uno u otro juego de lenguaje (de acuerdo a las diferentes posiciones en los mismos); (ii) estos análisis ponen de manifiesto que la inclusión en un juego de lenguaje supone, de parte de los participantes, la adquisición de una seguridad práctica para continuar de manera independiente, espontáneamente, en ausencia de fundamentos. La continuación independiente espontánea es un requerimiento impuesto por los juegos de lenguaje a los individuos, una condición para participar en los mismos. Esta observación tiene una consecuencia que desveló a Wittgenstein hasta el fin de sus días. En efecto, en términos de su análisis gramatical una buena cantidad de términos semánticos y mentales que en su superficie se presentan como sustantivos, no son en realidad nombres que hagan referencia a estados o procesos ("El significar no es un proceso que acompañe a esta palabra. Pues ningún proceso podría tener las consecuencias del significar algo" 78 ), sino que poseen una lógica indisociable de la de una interacción social compleja en la cual un individuo recibe un estatus social, de una manera rebatible y controvertible, a partir de ciertas "pruebas" que debe atravesar satisfactoriamente..$^{79}$ Pero este análisis gramatical, cuya apropiación en la cuadrícula de un análisis en términos de hechos disposicionales Wittgenstein rechazó preventivamente, corría también el riego de ser apropiado en términos conductistas, lo que haría de la comprensión el nombre de una clase de conductas o comportamientos, a expensas de la gramática del concepto. Este punto asoló a Wittgenstein ("¿no eres después de todo un conductista enmascarado?" ${ }^{80}$ ) porque creía que su esquema se volvía asî demasiado "mecánico", como sugiere Rush Rhees en el "Prólogo" de los

\footnotetext{
${ }^{78}$ Wittgenstein, L., Investigaciones filosóficas, parte II, p. 499.

${ }^{79}$ Estas "pruebas", cuya ejemplificación encontramos en el análisis de la lectura en Investigaciones filosóficas (ver $\int S 156$ y ss.), tienen la estructura de un rito de pasaje. La dificultad que Wittgenstein considera a propósito de una expresión como "la primera palabra que se lee" (ver \157) consiste en que no hay una consideración externa a la propia práctica, lo que podríamos llamar una consideración lógica, algorítmica, de la atribución del maestro al alumno de la habilidad de leer, los criterios de dicha atribución son inmanentes a la práctica de la enseñanza de la lectura.

${ }^{80}$ Ibidem, $\int 307$.
} 


\section{Cuadernos azuly marrón. ${ }^{81}$}

Wittgenstein creyó que la vertiente de una lectura conductista o excesivamente mecánica de su posición podía prevenirse por medio de un análisis del problema de la "ceguera para los colores", la "ceguera para los aspectos", o la "ceguera para el significado". Lo característico del "ciego" en este sentido es que puede aprender a desempeñarse de manera satisfactoria reconociendo las diversas referencias implicadas. Por ejemplo, quien fuera ciego para los aspectos vacilantes de una figura como la de Jastrow (la famosa figura pato-conejo), ${ }^{82}$ podría sin embargo aprender que la figura refiere a dos animales distintos, pudiendo obrar con una u otra de estas referencias, aun cuando no perciba la vacilación de los aspectos en la figura. Ahora bien, el criterio que nos permitiría reconocer a un ciego para los aspectos es que no podría realizar interjecciones como "iahora lo veo como pato! jahora lo veo como conejo!" La importancia de las observaciones sobre las diversas formas de "ceguera" puede apreciarse en la interpretación del aforismo "un estado interno requiere criterios externos" (Wittgenstein, Investigaciones filosóficas, \580). El mismo ha sido, naturalmente, un caballo de Troya para una interpretación conductista, pero es importante reparar en que este aforismo da pie a una interpretación dualista. Esta observación, leída a partir de lo que decíamos antes del conductismo, estaría en términos de una filosofía del juicio, necesariamente dualista. En efecto, para una lectura conductista 'dolor' sería el nombre de la clase de los comportamientos de dolor: puesto que veo que alguien tiene un comportamiento que cae dentro de la clase de conductas que corresponden a los criterios externos de un determinado estado interno, juqgo que posee ese estado interno. ${ }^{83}$ Las observaciones sobre la ceguera para los aspectos exhiben que la posición wittgensteiniana rechaza esta salida porque el austríaco no escoge entre los casilleros provistos por la concepción previa (externo-interno), como lo hace el conductismo con su famosa metáfora de la "caja negra", sino que hace estallar la distinción entre lo interior y lo exterior en cuanto tal. En efecto, los análisis de Wittgenstein muestran que formas interjectivas como “jahora lo veo!” (y también “jahora puedo seguir!”, crucial

\footnotetext{
81 Ver Wittgenstein, L., Cuadernos azul y marrón, pp. 20 y ss.

82 Ver Wittgenstein, L., Investigaciones filosóficas, parte II, p. 447.

${ }^{83}$ La posición de Norman Malcolm discurre en estos términos. Véase Karczmarczyk, P., El argumento del lenguaje privado a contrapelo, La Plata, Edulp, 2011, pp. 93 y ss.
} 
en el análisis de las reglas) constituyen respuestas a requerimientos que los juegos de lenguaje imponen sobre los pequeños cachorros humanos, ya que dichas formas interjectivas, en conjunto con el comportamiento adecuado, constituyen criterios a través de los cuales se atribuyen algunas capacidades cruciales para la incorporación a la vida en sociedad, a diversos juegos de lenguaje que, para retomar la metáfora de Investigaciones \18, cabría ubicar en el núcleo de la ciudadela lingüística. Se puede inferir entonces que sólo aquellos individuos que, testimoniándolo con estas interjecciones, encuentran unidad, consistencia y necesidad en el campo de lo que desde fuera podría verse como disperso y disgregado, esto es, sólo quienes son "ciegos a las alternativas" pueden encontrar un lugar en los juegos de lenguaje. Dicho de manera general, se es ciego para uno u otro aspecto, pero nunca para todo aspecto, puesto que esto implicaría el absurdo de un sujeto meramente contrapuesto a un exterior como un puro interior (sin exterior), presupuesto de toda filosofía del juicio que Wittgenstein cuestiona en su encarnación agustiniana desde el inicio de las Investigaciones. Al contrario, Wittgenstein nos lleva a pensar que una figura de esta clase es radicalmente imposible.

En resumen, y para concluir, entendemos que Wittgenstein impone una exigencia a la práctica de las ciencias sociales. La sobredeterminación, es decir, el desajuste entre la serie de las conductas (o los hechos brutos) y la serie social constituye un síntoma, indica la existencia de un problema teórico, pero su solución no pasa por la forma sujeto, como se lo ha querido presentar en influyentes interpretaciones, sino por inscribirlo en las formas de vida propiamente sociales. Las líneas finales de las Investigaciones filosóficas a propósito de la psicología resultan, en este sentido, muy sugerentes: “...en psicología existen métodos experimentales y confusión conceptual. (...) la presencia del método experimental nos hace creer que ya disponemos de los medios para librarnos de los problemas que nos inquietan; cuando en realidad problemas y métodos pasan de largo sin encontrarse". ${ }^{84}$ La observación podría extenderse al campo de los estudios sociales, una situación a la que han contribuido notablemente las interpretaciones dominantes de Wittgenstein montadas sobre la noción de reflexividad, y en consecuencia, sobre una concepción de lo social como la práctica de un sujeto.

${ }^{84}$ Investigaciones filosóficas, parte II, p. 527. 
¿En qué medida una filosofía que sostiene que "toda explicación tiene que desaparecer y sólo la descripción ha de ocupar su lugar. Y esta descripción recibe su luz, esto es, su finalidad, de los problemas filosóficos" 85 puede prestar un servicio a un abordaje científico de la realidad social? Creemos que esta observación debe leerse junto con la observación acerca de la situación de la psicología que venimos de considerar. En efecto, la descripción a la que alude Wittgenstein es aquella que despeja confusiones conceptuales, que son lo que hace que problemas y métodos "pasen de largo sin encontrarse". Si despejar el terreno de confusiones conceptuales no es, en cuanto tal, la operación científica de la definición del objeto de conocimiento, es un paso previo indispensable.

Martin Kusch ha realizado algunas observaciones interesantes a propósito de en qué medida una descripción gramatical, que establece relaciones internas, por ejemplo la relación entre una regla y sus aplicaciones en el interior de una práctica, es compatible con explicaciones causales. Autores como Baker y Hacker han sostenido que la naturaleza de este vínculo obtura la posibilidad de ensayar una explicación causal de una práctica, por la sencilla razón de que ello supondría buscar un intermediario entre la regla y sus aplicaciones, lo cual, tratándose de una relación interna, no puede redundar sino en un regreso o en una circularidad viciosa. ${ }^{86}$ Baker y Hacker llevan la razón al sostener que no se puede proveer un análisis causal de la relación entre la regla y sus aplicaciones, cuestión que aparece del todo clara a partir de las diferentes versiones que presentan el problema del seguimiento de reglas como "el problema del próximo caso". Al presentar el problema de las reglas como "el problema del próximo caso", se lo presenta como una forma de escepticismo semántico epistemológico, lo que implicaría conocimiento definido de la regla en cuestión y desconocimiento de sus aplicaciones. Pero aun reconociendo que la relación interna entre la regla y sus aplicaciones en una práctica no puede explicarse causalmente por medio de la formulación de la regla y a algunas interpretaciones sociales de la misma, que serían la causa de la aplicación de la regla (es el problema que hemos analizado a propósito de la

85 Wittgenstein, L., Investigaciones filosóficas, op. cit., \109.

${ }^{86}$ Baker, G. P. y Hacker, P. M. S., Scepticism, Rules and Language, Oxford, Oxford University Press, 1984. Puede consultarse un análisis de esta problemática en el capítulo 14 de Karczmarczyk, P., El argumento del lenguaje privado a contrapelo, ed. cit. 
"regla implicada"), todavía quedaría espacio para una explicación causal: "podemos concebir causas que podrían cambiar nuestra práctica en otra práctica. Tales causas podrían ser complejas e involucrar cambios en el mundo natural y en nuestro mundo social." 87 Un sociólogo está autorizado, en consecuencia, a preguntarse cuáles fueron las causas que estuvieron involucradas en la instauración de una práctica, "y está autorizado a sostener que, como un analista, encuentra a cada aplicación concreta de una regla potencialmente problemática: después de todo siempre es posible que una práctica dada sea empujada a transformarse en otra." 88

La reflexión que acabamos de reseñar presenta algunos importantes puntos de encuentro con las reflexiones epistemológicas que Maria Turchetto ha realizado a propósito de la lectura de Jacques Monod por Louis Althusser hacia fines de los años sesenta en su Curso de filosofía para científicos. Turchetto comenta la tesis de Monod según la cual la biología se tornó ciencia cuando aceptó el "postulado de objetividad" de la naturaleza, lo que llevó a rechazar sistemáticamente las interpretaciones de los fenómenos en términos de causas finales o proyectos ${ }^{89}$ Este postulado, que introdujeron en la física Galileo y Descartes con el principio de inercia, se afirmó mucho más tarde en el campo de la biología, en virtud del carácter teleonómico, es decir, de la evidente orientación hacia la supervivencia y a la reproducción, que encontramos en los sistemas vivos. Fue Darwin quien introdujo este postulado en la biología al subordinar la teleonomía a una invariancia (la selección natural). La teleonomía, para Monod, "es el resultado de una cierta organización de la materia cuya génesis es casual, es decir, no previsible". ${ }^{90}$ Sobre este último punto Monod puntualiza que al sostener que los seres vivos, en tanto clase, "no son previsibles a partir de los primeros principios" no pretende sugerir que no sean explicables a partir de esos principios, es decir, que los trasciendan, sino que no

${ }^{87}$ Kusch, Martin, "Rule-Scepticism and the Sociology of Scientific Knowledge. The Bloor-Lynch Debate Revisited”, Social Studies of Science, Vol. 34, N 4, 2004, p. 588.

88 Ibidem.

${ }^{99}$ Monod, Jacques, El azary la necesidad. Ensayo sobre la filosofía natural de la biología moderna, Barcelona, Planeta-Agostini, 1993, pp. 30-31.

90 Turchetto, Maria, "O que significa 'ciência da história", en Naves, Marcio Bilarinho (ed.), Presença de Althusser, Campinas, UNICAMP/IFICH, 2010, p. 80. 
son deducibles a priori a partir de los mismos. "La biósfera es, en mi opinión, señala Monod, imprevisible en el mismo grado que lo es la configuración particular de átomos que constituyen este guijarro que tengo en mi mano". ${ }^{91}$ Louis Althusser al comentar las tesis de Monod, nos recuerda Turchetto, indicaba que lo que Monod describía como una sola operación contiene en verdad dos pasos. El primero consiste en definir la teleonomía en términos de sistema vivo, y no en términos de "materia viva", es decir, definir la vida como efecto de una estructura, como una propiedad que emerge de una organización determinada de la materia, de la misma materia de la que se ocupa la física. El segundo paso es establecer el predominio de la emergencia sobre la teleonomía, es decir, el primado del encuentro azaroso sobre la forma. Lo que Althusser destacaba con esta distinción es la importancia del primer paso, en el sentido de disponer de una definición materialista de la vida como estructura para poder pensar el origen de la vida de manera no teleológica. En este nivel es donde se articulan la descripción y la explicación. En efecto, si sostuviéramos que el azar crea la vida, pero siguiéramos entendiendo por vida "algo ontológicamente diverso e irreductible al mundo no vivo, inorgánico, permaneceríamos prisioneros de lo que Monod define como un 'vitalismo metafísico' extraño a la objetividad científica." 92 El comentario de Althusser ayudó a discernir en la reflexión de Monod dos pasos fundadores de la objetividad científica, uno ligado a la construcción o definición del objeto de conocimiento, que rechaza la definición que contiene dualismos de principio, y en segundo lugar el rechazo de las causas finales.

Turchetto prosigue con una aguda exposición de la lectura de los dos pasos fundadores de la objetividad científica en la lectura que Althusser hiciera de Marx, en la que encuentra, en primer lugar, la definición de una formación social como un sistema complejo, lo que evita introducir dualismos de principio, ${ }^{93}$ de modo que el objeto de la historia queda definido como "conjuntos de relaciones sociales relativamente estables (capaces de autorreproducirse) estructurados 'en última instancia' a partir de las relaciones

${ }^{91}$ Monod, J., El azar y la necesidad, p. 52. Citado en Turchetto, M., op. cit., p. 81.

92 Turchetto, M., op. cit., p. 83.

${ }^{93}$ La definición del todo complejo estructurado con dominante tenía por objetivo destacar la materialidad propia de la superestructura. 
de producción, es decir, de aquellas relaciones sociales que se entablan en el intercambio orgánico con la naturaleza", ${ }^{94}$ lo que lleva a pensar a la sociedad como una estructura de relaciones conflictivas, con matrices de papeles dominantes y dominados. Y una historia de las relaciones sociales conflictuales es, en todo sentido, la 'bistoria de la lucha de clases'..." 95 . En segundo lugar, tenemos la tesis de la génesis aleatoria, ilustrada a propósito de la emergencia del capitalismo, concebida como el "encuentro de procesos históricos diversos que en un cierto punto cuajan, determinando la emergencia de la capacidad de autorreproducción de la relación social capitalista."96

Este ejemplo nos sirve, creemos, para ilustrar la posibilidad de un uso diverso de las reflexiones wittgensteinianas en el campo de las ciencias sociales.

\footnotetext{
94 Turchetto, M., op. cit., p. 88.

${ }^{95}$ Ibidem.

${ }^{96}$ Ibidem, p. 85.
} 